Revista Complutense de Historia de América ISSN: 1132-8312

http://dx.doi.org/10.5209/RCHA.61077

\title{
Las tierras bajas bolivianas como escenario de representación, siglos XIX-XXI
}

Anna Guiteras Mombiola ${ }^{1}$

En Bolivia, a diferencia del tradicional interés de los investigadores por la realidad andina, el devenir de los territorios y las sociedades de las denominadas tierras bajas $^{2}$ no ha merecido la misma atención por parte de los investigadores americanistas. Ello responde al hecho que tanto en el exterior como en la misma Bolivia existe una arraigada percepción andino-céntrica de la identidad nacional ${ }^{3}$ al haberse erigido como Estado independiente sobre la base territorial controlada efectivamente por la antigua Audiencia de Charcas ${ }^{4}$. Consecuencia de ello, los territorios situados al oriente de la cordillera andina han sido construidos históricamente como frontera(s) geográfica(s), socioeconómica(s) y étnica(s) desde el período colonial ${ }^{5}$ favoreciendo su persistencia en el imaginario colectivo boliviano en lo que se ha dado en llamar "lugares sin historia". Este hecho ha fomentado que hasta muy recientemente los procesos históricos, políticos, económicos, étnicos y sociales acaecidos en las tierras bajas hayan sido estudiados primordialmente desde la sociología, la antropología y las ciencias políticas. Ha sido en las dos últimas décadas que una importante cantidad de nuevas investigaciones están contribuyendo a llenar este vacío historiográfico y etnohistórico, particularmente grave en lo que se refiere al período tardocolonial y a la edad contemporánea ${ }^{6}$.

1 Taller de Estudios e Investigaciones Andino-Amazónicos (TEIAA) de la Universitat de Barcelona (España). Este dossier se inscribe en el proyecto de investigación $\mathrm{I}+\mathrm{D}+\mathrm{i}$ del Ministerio de Economía y Competitividad de España (HAR2015-64891-P, MINECO/FEDER, UE) que se desarrolla en el seno del TEIAA (2017SGR26) grupo de investigación consolidado por el Comissionat per a Universitats i Recerca del DIUE de la Generalitat de Catalunya.

E-mail: anna.guiteras@gmail.com

2 Adoptamos la expresión de "tierras bajas" (Lowlands) para referirnos a toda el área situada al este del altiplano boliviano porque, si bien dicho espacio es denominado Oriente en los países andinos, concordamos con aquellos autores que consideran el término inadecuado por existir en su interior diversos ecosistemas, poblaciones y recursos.

3 Villar - Combès, 2012: 7.

4 A pesar de la voluntad mostrada recientemente por historiadores y etnohistoriadores bolivianistas por presentar una visión más holística de los distintos procesos estudiados a nivel nacional, en la mayoría de estudios se sigue priorizando la realidad altiplánica siendo anecdótica y superficialmente tratado lo acaecido en las tierras bajas. Véase, por ejemplo, Carrera de Historia, 2015; Banco Central de Bolivia, 2015.

5 Los primeros trabajos que abordaron esta construcción de la frontera oriental en tanto que área de periferia, desarrollando lo que se llamó una "historia intersticial” son Saignes, 1985; Renard-Casevitz - Saignes - Taylor, 1988: 35-55.

6 Sin pretensión de ser exhaustiva véanse los trabajos de Roux, 2000; García Jordán, 2001; Roca, 2001; Combès, 2005, 2015a y 2016; Radding, 2008; Vallvé, 2010; Villar - Combès, 2012; Guiteras Mombiola, 2012; Van Valen, 2013; Córdoba - Bossert - Richard, 2015; Diez Gálvez, 2017. 
Hablar de tierras bajas bolivianas significa referirse prioritariamente al Chaco (al sureste) y a la Amazonía (al nor-noroeste). Espacios que se extienden sobre cerca de la mitad de la superficie del país y que han sido usualmente concebidos como 'desiertos', 'vacíos', territorios sin dueño e indomesticados, fronteras y 'tierras baldías' en los confines de la civilización, susceptibles de ser ocupadas. Por consiguiente, y a pesar de los intercambios comerciales, contactos interétnicos y choques culturales que desde antaño existen entre la cordillera andina y las distintas áreas de la llanura oriental, los variados grupos étnicos que habitan estas últimas son percibidos como exóticos, distantes, marginales y ajenos al quehacer nacional. Tales imágenes discursivas han sido construidas y reformuladas a lo largo del tiempo por un conjunto heterogéneo de actores sociales integrado por funcionarios, empresarios, militares, viajeros, colonos, migrantes, religiosos, investigadores e, incluso, los mismos grupos humanos oriundos de la región. Sin embargo, son escasos los estudios que aborden la elaboración de las representaciones (de pueblo, nación, región, clase, etnicidad) y en su (re)producción en las memorias sociales y culturales de estos sujetos históricos, entre el siglo XIX y la actualidad ${ }^{7}$.

La incorporación de los imaginarios, los significados, las acciones simbólicas y las interrelaciones grupales a los estudios interesados en las estructuras y los procesos sociales ha abierto nuevas perspectivas de análisis para la disciplina histórica $^{8}$. La adopción de la cultura nos permite interpretar la realidad formulada por los sujetos - de forma individual y/o colectiva- y entender la manera en que éstos pensaron, percibieron y dieron sentido al mundo que los rodeaba. Al mismo tiempo, este cambio de enfoque posibilita un acercamiento a métodos y prácticas propios de otras disciplinas, en particular de la antropología, lo que permite indagar en la conformación de las relaciones sociales a partir de ciertas prácticas culturales ${ }^{9}$. En este sentido, la comprensión de las sociedades a través de la cultura exige el estudio de las representaciones.

La representación es un concepto "poliédrico" que articula tres modos de relación con lo "social": el primero remite a la clasificación de las configuraciones intelectuales por las que los distintos grupos que componen una sociedad confeccionan su(s) realidad(es) de forma contradictoria; el segundo alude a las prácticas que permiten significarse simbólicamente y hacen reconocible una identidad social y una propia forma de "ser"; y el tercero atañe a las formas institucionalizadas y objetivadas gracias a las que los individuos y los colectivos dan visibilidad y permanencia al grupo, la comunidad o la clase ${ }^{10}$. La representación, entonces, implica mostrar aquello que está "presente" y, al mismo tiempo, atañe a la construcción y a la interpretación que hacen los sujetos de la realidad social. Se trata de una doble operación, transitiva y reflexiva: mientras la primera "presenta" lo ausente a través de imágenes, gestos y palabras -distinguiéndose lo que representa y de lo es representado-, la segunda concierne a los actos, acciones y motivaciones que dotan de presencia, que dan lugar a su auto-representación ${ }^{11}$. A su vez, estas configuraciones intelectuales se transmiten y persisten a través de la memoria, entendida como la reconstrucción del pasado

\footnotetext{
Son excepciones los trabajos de Combès, 2012 y 2015b; García Jordán, 2012, 2016 y 2017; Lema, 2014; Guiteras Mombiola, 2015; Córdoba, 2015.

Chartier, 1999; Burke, 2000.

Burke, 2000: 241-249; Martínez Martín, 2007.

Chartier, 1993; 1999: 56-57.

Lefebvre, 1983: 167-168 y 199-201; Marín, 1994: 37 y 342; Désesquelles, 2001: 7.
} 
por parte de un grupo. En este sentido, la memoria colectiva da lugar a la formación de identidades sociales y grupales que se inscriben en narraciones -o historias- individuales y colectivas $\mathrm{y}$, simultáneamente, son definidas por elementos comunes y recuerdos -y olvidos- compartidos susceptibles de apropiación y sucesivas alteraciones $^{12}$. Finalmente, el concepto de la representación permite la interrelación de la estructura socioeconómica y las acciones de los grupos sociales. La posición de los agentes sociales en el ámbito económico se traduce en divisiones sociales y establece condiciones para forjar diferentes formas de identidad que, al mismo tiempo, establecen los principios para determinar las relaciones y las prácticas sociales; prácticas entendidas como formas "de hacer" que se desarrollan en un determinado universo simbólico que afecta a las acciones de producción, negociación, transferencia y contestación de las representaciones realizadas por los actores sociales ${ }^{13}$.

Objetivo del presente dossier es propiciar un debate interdisciplinario en torno a la producción y circulación de la(s) historia(s), la(s) memoria(s) y la(s) representación(es) discursivas y visuales centradas en las poblaciones de las tierras bajas bolivianas -indígenas mayoritariamente, pero no exclusivamente- desde fines del siglo XIX hasta la actualidad. El dossier reúne la versión final de algunos de los trabajos presentados y discutidos en el marco de los simposios "Las tierras bajas bolivianas como representación, siglos XVI-XXI" y "Amazonía, Rondonia e Iténez/ Guaporé" de las II Jornadas de Antropología, Historia y Arqueología de Tierras Bajas celebradas en Santa Cruz de la Sierra (Bolivia) en octubre de 2015. Los tres estudios que constituyen el dossier dirigen su atención a las dos grandes áreas geográficas de las tierras bajas bolivianas a partir del análisis de fuentes visuales, escritas y orales, y con distintos enfoques metodológicos. Desde la perspectiva de la historia y la antropología, los artículos abordan las representaciones étnicas, identitarias, de nación y de clase en sus dos facetas: por un lado, la construcción de representaciones sobre la población -nativa, trabajadora, nacional- por parte de aquellos agentes que poseen el poder de categorizar y clasificar -viajeros, empresarios, autoridades públicas-; y, por otro lado, las auto-representaciones que cada grupo hace de sí mismo, aceptando, negociando o rechazando tales clasificaciones, y que le dotan de pertenencia y significación tanto a nivel colectivo como individual.

El primero de los artículos, firmado por la etnohistoriadora Isabelle Combès, analiza una colección de fotografías de indígenas del Chaco boliviano, así como las notas inéditas que la acompañan, tomadas por el ingeniero francés Jean-Baptiste Vaudry recién inaugurado el siglo XX. La autora indaga en la realidad socioétnica de la frontera chaqueña en el momento en que se estaban definiendo los límites internacionales entre Bolivia y Argentina y, al mismo tiempo, se expandía la frontera interna de colonización. El Chaco era habitado por chiriguanos (actuales guaraníes), noctenes (hoy weenhayek), matacos y tapietes (wichís y nivaclés) y tobas, quienes compartían el espacio con distintos agentes del frente colonizador: misioneros franciscanos, soldados y colonos criollos. Todos ellos son actores con los que Vaudry interaccionó. Combès muestra cómo la obra fotográfica de esta suerte de etnólogo aficionado reproduce gráficamente la clasificación étnica vigente entre las sociedades de frontera (criollas, pero también indígenas) y por la que las poblaciones eran identificadas según su grado de cercanía a la "civilización" o, por el contrario, a la

Nora, 1989: 8-9; Ricoeur, 1999: 13-22, 33, 38 y 46; Burke, 2000: 66-71.

De Certeau, 2000: xlii-liii. 
"barbarie". Más interesante es el hecho que las fotografías y sus anotaciones rompen con los discursos maniqueos de muchos viajeros europeos y latinoamericanos que recorrieron la región y en cuyos relatos se reducía la pluralidad étnica a una imagen genérica del indio, en este caso, chaqueño, y se separaba el mundo de los indios del mundo de los blancos. Sostiene Combès que Vaudry retrata aquello que vio y con ello "muestra personas con historia, con individualidad, con personalidad" que conviven y se interrelacionan más allá de su origen étnico y que integran una sociedad compleja y amalgamada. Una visión nada común en la época pero que ilustra, como concluye la autora, "la realidad porosa fluida y movediza" de la vida en la frontera.

Permaneciendo en un espacio de frontera, pero desplazándonos hacia el norte amazónico, el segundo artículo de autoría de la historiadora Kathryn Lehman, se acerca a la construcción y posterior modificación de la representación de los trabajadores de la principal empresa gomera boliviana: la Casa Suárez. A partir del análisis del fondo documental de esta sociedad comercial y por medio del uso de la 'etnografía de y en el archivo' como herramienta metodológica, la autora aborda el impacto que tuvieron en la lógica empresarial de la Casa Suárez la crisis de la economía gomera y el temor a posibles nuevas agresiones territoriales por parte de los países vecinos en las décadas de 1920 a 1940. La autora recuerda que la falta de presencia estatal en la región conllevó su ocupación de facto por parte de trabajadores gomeros bolivianos, peruanos y brasileños que poco sabían de los límites fronterizos establecidos entre sus países de origen y que terminaría ocasionando un grave conflicto internacional a inicios del siglo XX. Lehman plantea que tanto la memoria de este pasado bélico -y el temor a su futura repetición- como el colapso económico que comportó la caída del precio de la goma elástica dieron lugar a un contexto de incertidumbre que afectó sustancialmente la percepción que tenían los empresarios gomeros sobre la fuerza laboral no cualificada. Mozos, siringueros y fregueses -en su mayoría indígenas procedentes de todas las tierras bajas, pero también de origen mestizo- dejaron de ser concebidos como elementos meramente productivos y fácilmente substituibles, para devenir un colectivo protegido y valorizado del que dependía no sólo la supervivencia económica de la Casa Suárez, sino también el resguardo de la soberanía nacional.

Cierra este dossier una sugerente propuesta relativa a la construcción de la memoria y de la historia desde una perspectiva etnográfica, de la mano del antropólogo Charles Sturtevant. Su estudio se centra en las múltiples y contradictorias percepciones que existen en San Ignacio de Mojos - capital folklórica de los llanos de Mojos y capital espiritual de las misiones jesuíticas del Cono Sur-sobre la figura de Lorenza Congo: mujer, indígena, propietaria y adinerada que vivió durante buena parte del siglo XX. Convertida en el actual símbolo o ícono de la identidad étnica ignaciana, al autor no le interesa proporcionarnos su historia, sino reflexionar sobre la narración de las historias que circulan sobre ella. Sturtevant sostiene que el hecho de contar tales historias cumple determinadas funciones para cada uno de los narradores que permiten, por un lado, posicionar socialmente a los actores y, por otro lado, definir identidades grupales, en el aspecto étnico, pero también en lo local y lo nacional. A nivel individual, el conocimiento de su figura a partir de la historia oral o del uso de fuentes documentales permite cimentar aspiraciones sociales y/o políticas y obtener reconocimiento al interior de la comunidad o ante personas e instituciones foráneas. A nivel colectivo, la evocación de la "Mama Congo" refleja las vicisitudes sufridas por la población indígena durante el período republicano bajo el yugo del dominio 
criollo y, a su vez, se articula con sus luchas actuales, frente a un Estado que también sustenta sus políticas de desarrollo económico y educativo en esa misma figura. En definitiva, Sturtevant explora la circulación simultánea de las narraciones contradictorias sobre un personaje que ha devenido la representación personificada de todos los ignacianos.

A tiempo de concluir esta presentación sólo me queda esperar que los artículos aquí recogidos, desde sus particularidades y miradas, enfoques y metodologías diversas, contribuyan a reflexionar en torno de los procesos de producción y circulación de las imágenes discursivas sobre las poblaciones de las tierras bajas de Bolivia en distintos contextos socioeconómicos regionales y distintas coyunturas políticas y, a su vez, abrir nuevas líneas de análisis sobre las realidades sociales por medio del estudio de la cultura, la memoria y la representación.

\section{Referencias bibliográficas}

Banco Central de Bolivia. Historia monetaria de Bolivia, vols. 1 y 2. La Paz: Banco Central de Bolivia, 2015.

Burke, Peter. Formas de historia cultural. Madrid: Alianza Editorial, 2000.

Carrera de Historia. Bolivia, su historia, vols. 1-6. La Paz: La Razón, 2015.

Chartier, Roger. "Representaciones y prácticas culturales en la Europa moderna. Conversación con Roger Chartier". Manuscrits, nº 11 (1993), 29-40.

Chartier, Roger. El mundo como representación. Estudios sobre historia cultural. Barcelona: Editorial Gedisa, 1999.

Combès, Isabelle. Etno-historias del Isoso. Cháné y chiriguanos en el Chaco boliviano (siglos XVI a XX). La Paz: IFEA - PIEB, 2005.

— "Etiquetas versus neologismos: la antropología como representación". Boletín Americanista, $\mathrm{n}^{\circ} 65$ (2012), 131-144.

- Notas de etnohistoria (Chaco y Chiquitania). Santa Cruz de la Sierra: Biblioteca del Museo de Historia, 2015a.

— "Filtros étnicos en la historiografía indígena del Chaco boliviano". En El mundo latinoamericano como representación, siglos $X I X-X X$, editado por García Jordán, Pilar. Barcelona: Publicacions i Edicions UB - TEIAA - IFEA, 2015b, 17-36.

- Historia del pérfido Cuñamboy. La cordillera chiriguana en los albores de la independencia de Bolivia. Cochabamba: Editorial Itinerarios, 2016.

Córdoba, Lorena. "Barbarie en plural: percepciones del indígena en el auge cauchero boliviano". Journal de la société des américannistes, 101, 1-2, 2015, pp. 173-202. DOI: $10.4000 /$ jsa. 14384

Córdoba, Lorena - Bossert, Federico - Richard, Nicolás (eds.). Capitalismo em las selvas. Enclaves industriales em el Chaco y la Amazonía indígenas (1850-1950). San Pedro de Atacama: Ediciones del Desierto, 2015.

De Certeau, Michel. La invención de lo cotidiano. 1. Artes de hacer. México: Universidad Iberoamericana, 2000.

Désesquelles, Anne-Claire. La représentation. Paris: Ellipses, 2001.

Diez Gálvez, María José. Las misiones de Mojos: el barroco en la frontera, tomos 1 y 2. Cochabamba: Ed. Itinerarios - Instituto de Misionología, 2017.

García Jordán, Pilar. Cruz y arado, fusiles y discursos. La construcción de los Orientes en el Perú y Bolivia, 1820-1940. Lima: IFEA - IEP, 2001. 
— “La representación de los Guarayos en la 'Esposizione d'Arte Sacra e delle Missioni ed Opere Cattoliche’ (Turín, 1898)”. Boletín Americanista, nº 65 (2012), 107-129.

— "Una representación visual de los Chiriguano en la exposición misional de Turín, 1898". Hispania Sacra, vol. LXVIII, n 138 (julio-diciembre 2016), 735-745. DOI: 10.3989/ hs. 2016.048

— “El 'espacio blanco' recorrido por d'Orbigny, 1831-1832. Una representación de Guarayos y sus habitantes". Revista Complutense de Historia de América, nº 43 (2017), 237-258. DOI: 10.5209/RCHA.56733

Guiteras Mombiola, Anna. De los llanos de Mojos a las cachuelas del Beni, 1842-1938. Cochabamba: Ed. Itinerarios - Instituto de Misionología - ABNB, 2012.

— "De ciudadanos a impúberes sociales, del capital inútil al elemento productivo. Discursos sobre los indígenas del departamento del Beni (Bolivia, 1842-1950)”. En El mundo latinoamericano como representación, siglos $X I X-X X$, editado por García Jordán, Pilar. Barcelona: Publicacions i Edicions UB - TEIAA - IFEA, 2015, 57-79.

Lefebvre, Henri. La presencia y la ausencia. Contribución a la teoría de las representaciones. México: Fondo de Cultura Económica, 1983.

Lema, Ana María. "El hombre del nuevo mundo: Indígenas de las tierras bajas bolivianas en la mirada de Alcide d'Orbigny". Caravelle. Cahiers du Monde Hispanique et LusoBresilien, $\mathrm{n}^{\mathrm{o}} 103$ (2014), 67-83. DOI: 10.4000/caravelle.973

Marín, Louis. De la représentation. Paris: Gallimard - Le Seuil, 1994.

Martínez Martín, Jesús. "Historia socio-cultural. El tiempo de la historia de la cultura". Revista de Historia Jerónimo Zurita, nº 82 (2007), 237-252.

Nora, Pierre. "Between memory and history: les lieux de mémoire". Representations, no 26 (1989), 7-24.

Radding, Cynthia. Paisajes de poder e identidad: fronteras imperiales en el desierto de Sonora y bosques de la Amazonía. México: CIESAS - El Colegio de Sonora - UAM, Azcapotzalco, 2008.

Renard-Casevitz, France-Marie - Saignes, Thierry - Taylor, Anne-Christine. Al Este de los Andes. Relaciones entre sociedades amazónicas y andinas entre los siglos XV y XVII. Quito: Abya-Yala, 1988.

Ricoeur, Paul, La lectura del tiempo pasado: memoria y olvido. Madrid: Arrecife producciones, 1999.

Roca, José Luis. Economía y sociedad en el Oriente boliviano, siglos XVI-XX. Santa Cruz de la Sierra: Cotas Ltd., 2001.

Roux, Jean Claude. La Bolivie orientale. Confines inexplorés, battue aux Indiens et économie de pillage. Paris: L'Harmattan, 2000.

Saignes, Thierry. Los Andes Orientales: Historia de un olvido. La Paz: CERES - IFEA, 1985.

Vallvé, Frederic. "The Impact of the Rubber boom on the Indigenous Peoples of the Bolivian Lowlands (1850-1920)". Tesis doctoral, Georgetown University, 2010.

Van Valen, Gary. Indigenous Agency in the Amazon. The Mojos in Liberal and Rubber-boom Bolivia, 1842-1932. Tucson: The University of Arizona Press, 2013.

Villar, Diego - Combès, Isabelle (comps.). Las tierras bajas de Bolivia: miradas históricas y antropológicas. Santa Cruz de la Sierra: Ed. El País, 2012. 